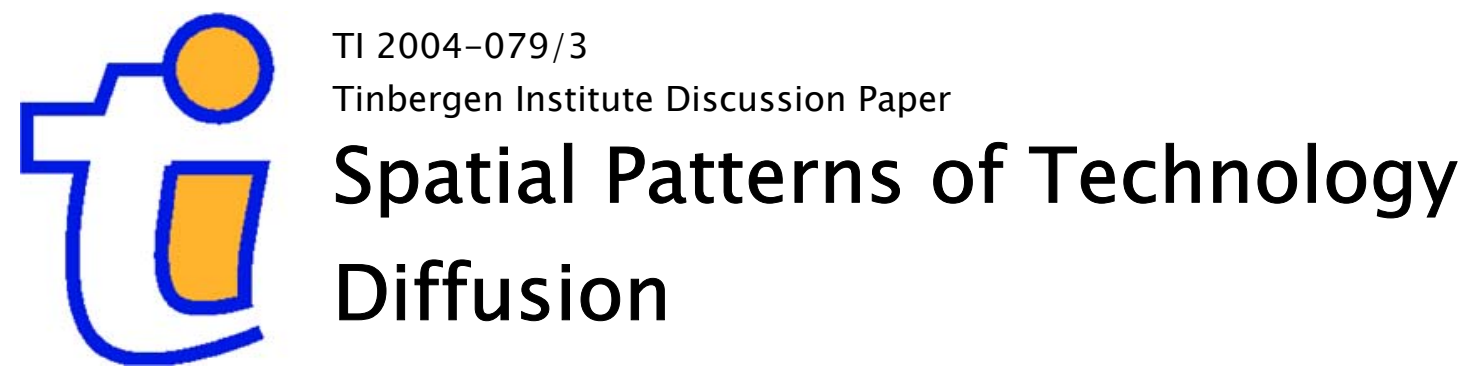

Maria Abreul,2

Henri L.F. de Groot ${ }^{1,2}$

Raymond J.G.M. Florax ${ }^{1,3}$

1 Vrije Universiteit Amsterdam,

2 Tinbergen Institute,

3 Purdue University. 


\section{Tinbergen Institute}

The Tinbergen Institute is the institute for economic research of the Erasmus Universiteit Rotterdam, Universiteit van Amsterdam, and Vrije Universiteit Amsterdam.

Tinbergen Institute Amsterdam

Roetersstraat 31

1018 WB Amsterdam

The Netherlands

Tel.: $\quad+31(0) 205513500$

Fax: $\quad+31(0) 205513555$

Tinbergen Institute Rotterdam

Burg. Oudlaan 50

3062 PA Rotterdam

The Netherlands

Tel.: $\quad+31(0) 104088900$

Fax: $\quad+31(0) 104089031$

Please send questions and/or remarks of nonscientific nature to driessen@tinbergen.nl.

Most TI discussion papers can be downloaded at http://www.tinbergen.nl. 


\title{
Spatial Patterns of Technology Diffusion: An Empirical Analysis Using TFP
}

\author{
Maria Abreu* Henri L.F. de Groot ${ }^{\dagger} \quad$ Raymond J.G.M. Florax ${ }^{\ddagger}$
}

9 July, 2004

\begin{abstract}
In this paper we employ techniques developed in spatial econometrics to analyse spatial patterns of technology diffusion, to detect clusters and to estimate theoretical models that incorporate space explicitly. These techniques correct for misspecifications resulting from the omission of spatial linkages in standard empirical models of economic growth. Our dataset consists of TFP estimates for 73 countries over the period 19602000 , and we find that TFP growth rates and levels are positively autocorrelated over space, meaning that high or low values tend to be clustered. We also find that TFP levels are becoming more clustered over time, suggesting the possibility that technology levels are converging locally. Estimation of spatial versions of the Nelson and Phelps (1966) model shows that the impact of being located close to a country with high TFP growth rates is positive and substantial.
\end{abstract}

JEL: I2, O4, C21. Keywords: human capital, technology diffusion, spatial econometrics.

\section{Introduction}

Is there a spatial dimension to the flow of technology across country borders? Our aim is to investigate this question using exploratory spatial data analysis and spatial econometric techniques. Following Coe and Helpman (1995), Keller (2001), Benhabib and Spiegel (1994, 2002) and others we study the effect of knowledge spillovers on total factor productivity (TFP).

There are two broad schools of thought in the literature on the diffusion of technology across countries. The first one emphasizes the importance of absorptive capacity, that is,

\footnotetext{
${ }^{*}$ Free University and Tinbergen Institute, The Netherlands. Address: De Boelelaan 1105, 1081 HV Amsterdam, The Netherlands. E-mail: mabreu@feweb.vu.nl.

${ }^{\dagger}$ Free University and Tinbergen Institute, The Netherlands. E-mail: hgroot@feweb.vu.nl.

‡Free University, The Netherlands and Purdue University, USA. E-mail: rflorax@feweb.vu.nl.
} 
the ability of nations to adopt foreign technology for use in the domestic market. This view is based on the idea that there is a common pool of knowledge to which all countries have access, so that technology diffusion is constrained only by the receiving country's ability to understand and make use of the new technology. A prominent example of this view is the Nelson and Phelps (1966) model. The rate of adoption of new technology depends on the capacity of individuals and firms to implement new ideas, and on the gap between the technology they are currently using and the state of the art. The determinant of absorptive capacity in this case is the level of education.

Several empirical studies have found evidence in support of the absorptive capacity view. Benhabib and Spiegel (1994) use a growth-accounting method to study the effect of human capital on productivity growth, and find that human capital has a positive and statistically significant effect when interacted with the technology gap (as in Nelson and Phelps, 1966). Eaton and Kortum (1996) find that inward technology flows (measured by patent citations) are increasing in the level of human capital. Xu (2000) finds that richer countries benefit from hosting US multinational subsidiaries while poor countries do not benefit as much, and that the discrepancy can be explained in terms of the level of human capital in the host country.

Absorptive capacity may also depend on the level of domestic R\&D, so that domestic innovation must already have reached a critical level before foreign technology can be successfully adopted. Cohen and Levinthal (1989) show that firms need to substantially invest in $R \& D$ in order to understand and evaluate new technological trends and innovations. Griffith et al. (2000) find that TFP growth is negatively correlated with the productivity gap (to the technology leader), particularly when the productivity gap is interacted with the level of domestic R\&D.

Institutions may also influence absorptive capacity, an idea highlighted by the literature on innovation systems (Acs and Varga, 2002). Government policies to promote research, networks of scientists and good universities all encourage $R \& D$ and the adoption of foreign technology. Parente and Prescott (2000) argue that while technology is global, countries differ in their resistance to adopt new technologies, due to the greater or lesser influence of domestic lobbies and state bureaucracies.

The second view on technology diffusion across countries emphasizes the importance of bilateral ties. Countries have different stocks of knowledge, and diffusion occurs through bilateral channels such as trade and Foreign Direct Investment (FDI). In general two mechanisms have been identified: (1) direct learning about foreign technology, and (2) employing specialised and advanced intermediate products developed abroad.

Direct learning requires a channel of communication between the two parties, especially since some knowledge may be tacit in that it cannot be codified and can only be passed from one person to another (Polanyi, 1958). There is some evidence that non-codified knowledge 
has a localised pattern. Feldman and Lichtenberg (1997) construct a measure of the tacitness of knowledge for a study of R\&D activities in the EU, and find that the degree of tacitness of knowledge has an effect on the location of R\&D activities.

Codified forms of knowledge (patents, blueprints, articles in scientific journals) may also have a localised pattern. Eaton and Kortum (1996) study patenting activity in the OECD, and find that patent citations decline with geographical distance (although this finding may be due to the importance of within-country citations). Jaffe and Trajtenberg (2000) also find that intra-national spillovers (measured by patent citations) are larger than those between countries. Part of this effect may be due to the sharing of a common language: Keller (2001) finds that bilateral language skills explain about $16 \%$ of bilateral technology diffusion.

Direct learning in the form of tacit knowledge or via blueprints and articles can be described as active technology diffusion (Keller, 2002). The other mechanism, known as passive diffusion, is the purchase and use in production of intermediate goods with embodied foreign knowledge. It is still a form of knowledge transfer, because it allows the buyer to implicitly use foreign technology in production. It may also encourage further domestic innovation through reverse engineering, or because it facilities domestic R\&D (e.g., imports of computer equipment).

The empirical literature on technology diffusion has focused on trade and FDI. Coe and Helpman (1995) study the impact of trade on technology diffusion, and find that international R\&D spillovers are related to the composition of imports (whether imports originated in high or low technology countries) and that the overall level of imports is also important. Eaton and Kortum (1996) and Keller (1998) provide evidence to suggest that import- composition may not matter much once distance has been accounted for. Xu and Wang (1999) show that the import-composition effect is robust when one considers trade in capital goods only, instead of trade in all manufacturing goods. Keller (2001) finds that $69 \%$ of bilateral technology diffusion can be explained by trade patterns (and trade can be shown to be a function of bilateral distance).

In short, the empirical literature has found considerable evidence to suggest that technology diffusion may follow a spatial pattern, and that country characteristics such as the stock of human capital and the level of domestic $R \& D$ affect the rate at which a country adopts foreign technology. We combine the two approaches by modifying the Nelson and Phelps (1966) model to allow for spatial dependence in TFP growth rates. Spatial econometric techniques allow us to identify the type of spatial dependence present in the model and to estimate it consistently. Moreover, exploratory spatial data analysis techniques allow us to identify clusters and other "anomalies" such as spatial outliers, and to present the results visually in the form of Moran scatterplots and Moran cluster maps.

Spatial econometrics has mainly been used in applications at the level of regions, with several authors applying the techniques to income levels and growth rates, mostly in the 
context of models of income convergence. Rey and Montouri (1999) study income convergence among the states of the US over the period 1929-1994, and find strong patterns of global and local spatial autocorrelation, with some evidence that temporal changes in spatial autocorrelation are associated with changes in regional income dispersion. Mossi et al. (2003) use spatial data analysis techniques and Markov transition matrices to study growth and inequality in the regions of Brazil. They find evidence of the existence of two spatial clusters: a low income one in the Northeast and a high-income one in the Southeast. LopezBazo et al. (1999), Le Gallo et al. (2003) and Fingleton (1999) apply spatial econometric tools to the analysis of the convergence in the European regions, and find evidence of spatial dependence.

Studies at the country level are scarcer. Moreno and Trehan (1997) find that a country's growth rate is closely related to that of nearby countries, and that trade alone cannot explain the extent of the spatial dependence. Ramírez and Loboguerrero (2002) study spatial dependence in a sample of 98 countries over three decades (1965-1995) and find that spillover effects are important for economic growth, after controlling for a number of standard social, political and economic variables. Florax and Nijkamp (2004) extend the Mankiw, Romer and Weil (1992) model to allow for spatial dependence and spatial heterogeneity. They find evidence of spatial clustering of countries with similar levels of GDP per capita, and conclude that different convergence rates apply to fast and slow growing economies.

There has, to our knowledge, been no spatial econometric analysis of TFP either at the regional or country level, and we aim to fill this gap. The remainder of the paper is organised as follows. Section 2 describes our data set, and the method used to construct our measure of TFP. In Section 3 we apply spatial data analysis techniques to investigate overall spatial patterns in the data, and the presence of clusters and outliers. Section 4 discusses the Nelson and Phelps (1966) model, and alternative specifications that allow for spatial dependence. Section 5 presents our empirical results, and Section 6 concludes.

\section{Data}

We construct our measure of TFP using a constant returns to scale Cobb-Douglas production function, with the capital share of income set to $1 / 3$ and the labour share set to $2 / 3$. Gollin (2002) shows that these are reasonable estimates, given that the share of labour lies between 0.65 and 0.85 for a large cross-section of developed and developing countries. We then calculate TFP as a residual:

$$
\ln T F P_{i t}=\ln Y_{i t}-\frac{1}{3} \ln K_{i t}-\frac{2}{3} \ln L_{i t},
$$


where $Y_{i t}$ is real output in country $i$ and time $t, K_{i t}$ is the capital stock, and $L_{i t}$ is the total number of workers.

Our capital stock series is constructed using the perpetual inventory method:

$$
K_{i t}=\sum_{j=0}^{t}(1-\delta)^{t-j} I_{i j}+(1-\delta)^{t} K_{i 0}
$$

where $I_{i t}$ is aggregate investment in physical capital in country $i$ and time $t$, and $\delta$ is the rate of depreciation. An estimate of the initial capital stock is obtained from the expression for the capital/output ratio in the steady state:

$$
\frac{K_{i 0}}{Y_{i 0}}=\frac{(I / Y)_{i}}{\gamma+\delta+n_{i}}
$$

where $Y_{i 0}$ output in 1960, $(I / Y)_{i}$ is the investment share of output, $\gamma$ is the growth rate of output per capita in the steady state, and $n_{i}$ is the rate of population growth. Following Mankiw, Romer and Weil (1992) we assume a fixed value of $\gamma+\delta$, although in our case we assume $\gamma=0.02$ and $\delta=0.07$, a higher depreciation rate which is in line with recent estimates from microeconomic studies. ${ }^{1}$ We use 1960-1965 averages of the investment share and the population growth rate. The investment data is taken from PWT 6.1, using the real share of investment in GDP multiplied by GDP in constant PPPs.

As a robustness check we also tried varying the initial capital stock, the rate of depreciation (between 0.03-0.08), and the source of investment data (we also used the gross fixed capital formation series from the WDI 2002), all of which have little effect on the estimates. Our estimates of the capital stock are highly correlated with more sophisticated series based on disaggregated data such as the PWT 5.6 capital stock series; see Scarpetta et al. (2000) and Easterly and Levine (2002). ${ }^{2}$

Our labour series is taken from PWT 6.1, and consists of the total number of workers. Our analysis also requires human capital data; we use the average years of schooling in the population aged 25 and over from the Barro and Lee (2001) dataset.

Our dataset covers a sample of 73 countries over the period 1960-2000, but it is somewhat restricted for two reasons. First, only countries whose borders did not change between 1960 and 2000 can be included, because the weights matrix used in the spatial analysis is exogenous and must remain constant over the entire period. Second, aggregate investment data is only available for a small sample of countries. ${ }^{3}$

\footnotetext{
${ }^{1}$ See Fraumeni (1997), Whelan (2002) and Oulton and Srinivasan (2003) for a discussion on the empirical methods used to estimate rates of capital depreciation and some recent estimates.

${ }^{2}$ Details are available from the authors upon request.

${ }^{3}$ Table 1 in the Appendix contains a list of countries included in the analysis, ISO country codes used to identify the observations, and our TFP estimates.
} 


\section{Exploratory Analysis}

In Figure 1 we have plotted the growth rate of TFP over the period 1960-2000 against the logarithm of TFP in 1960. The result is a pattern frequently observed in the literature. There is a slight negative correlation, indicating some tendency towards convergence in TFP levels. ${ }^{4}$ Figure 2 is a scatterplot of the growth rate of TFP against the logarithm of schooling in 1960. In this case the correlation is more pronounced and positive, consistent with the hypothesis that higher schooling is associated with greater technology transfer.

The spatial distribution of TFP growth rates can also be seen in Figure 3. Countries with high TFP growth rates (above 2.5\%) over this period are Hong Kong, South Korea, Thailand, Japan, Ireland, Pakistan, Mauritius and Barbados. Note the contrast with the distribution in Figure 4, showing the logarithm of TFP in 1960: countries that lag behind in terms of TFP in 1960 experience rapid TFP growth over the period 1960-2000.

A similar pattern is apparent when comparing Figures 5 and 6 , showing the spatial distribution of schooling growth rates and schooling in 1960. There is some evidence of a spatial clustering of schooling levels in 1960, particularly in Europe and Latin America. A rapid improvement in the average years of schooling of the population is visible in Africa, South Asia and South-East Asia.

Spatial autocorrelation can be defined as the coincidence of value similarity with locational similarity (Anselin, 2001). There is positive spatial autocorrelation when high or low values of a variable tend to cluster together in space, and negative spatial autocorrelation if high values are surrounded by low values and vice-versa. A standard measure for spatial autocorrelation is the Moran's $I$ statistic. For a variable $x$ at time $t$ it is given by:

$$
I_{t}=\frac{n}{S_{0}} \frac{\sum_{i=1}^{n} \sum_{j=1}^{n} w_{i j}\left(x_{i, t}-\mu_{t}\right)\left(x_{j, t}-\mu_{t}\right)}{\sum_{i=1}^{n}\left(x_{i, t}-\mu_{t}\right)^{2}}
$$

where $x_{i, t}$ is the observation for country $i$ at time $t, \mu_{t}$ is the mean value of variable $x$ at time $t, n$ is the number of countries, $w_{i j}$ is one element of the spatial weights matrix $W$ and $S_{0}$ is a scaling factor equal to the sum of all elements of $W$. The spatial weights matrix contains information on the spatial configuration of the countries in the sample, and in our case it has been constructed as follows:

$$
\begin{cases}w_{i j}=d_{i j}^{-1} & \text { if } d_{i j}<6000 \text { miles } \\ w_{i j}=0 & \text { otherwise }\end{cases}
$$

where $d_{i j}$ is the distance between the centroids of countries $i$ and $j$ in miles. We follow

\footnotetext{
${ }^{4}$ In talking about convergence we consistently refer to $\beta$-convergence (as opposed to $\sigma$-convergence). See Barro and Sala-i-Martin (1995) for a discussion on the different concepts of convergence.
} 
common practice in assuming that the diagonal elements of $W$ are zero; implying there is no self-association.

The critical cut-off distance of 6000 miles implies that we expect all spatial interactions above this distance to be negligible. Our matrix is constructed in such a way that interactions between countries decline with distance, and we chose a cut-off distance of 6000 miles to take into account spatial interactions between the main technology leaders. So for instance, the distance between the centroids of the US and Europe is 5906 miles, between the US and Brazil 5992 miles and between the US and Japan 5483 miles. Similarly, the distance between the centre of Europe and Brazil is 5766 miles, between Europe and South Africa 5483 miles, and between Europe and Japan 5944 miles.

Table 2 lists the Moran's $I$ statistics and associated $z$ - and $p$-values for three variables: (1) TFP growth (1960-2000), (2) $\ln ($ TFP) in 1960 and (3) $\ln ($ TFP) in 2000. Positive values of Moran's $I$ indicate positive spatial autocorrelation, implying that similar values are more spatially clustered than could have been caused by chance. Negative values indicating negative spatial autocorrelation, or a clustering of dissimilar values. We have used the normal distribution to calculate the probabilities of the $z$ values, since Wald tests do not reject normality for the variables TFP growth, $\ln (\mathrm{TFP})$ in 1960 and $\ln (\mathrm{TFP})$ in 2000.

In all three cases the $z$-value for Moran's $I$ is positive and significant, indicating the presence of positive spatial autocorrelation. The statistic is higher for TFP in 2000 than in 1960, indicating that TFP levels are becoming more clustered over time, and suggesting that convergence clubs may have a spatial dimension. Note also that TFP levels are more spatially autocorrelated than the TFP growth rates.

These results can also be displayed visually using a Moran scatterplot (Anselin, 1996), which plots the spatial lag $W z$ against $z$, where $z$ is the vector of observations for variable $x$ in deviations from the mean and scaled by the standard deviation. Moran's $I$ is formally equivalent to the slope coefficient of the linear regression of $W z$ on $z$, using a rowstandardised weights matrix (a matrix is row-standardised when the elements $w_{i j}$ in each row sum to 1). Figures 7, 8 and 9 are Moran scatterplots for the variables TFP growth, $\ln (\mathrm{TFP})$ in 1960 and $\ln (\mathrm{TFP})$ in 2000, respectively. The four quadrants in the plot provide a classification of the observations into four types of spatial association: high values located next to high values (upper right-hand corner), low values located next to low values (lower left-hand corner), high values located next to low values (lower right-hand corner), and low values located next to high values (upper left-hand corner).

Consider the scatterplot in Figure 7 for TFP growth rates over the period 1960-2000. ${ }^{5}$ The Moran's $I$ statistic in Table 2 already indicated a low degree of spatial autocorrelation, and this can be seen in the plot (the observations are fairly scattered). There are two interesting results: a significant number of African countries are situated in the lower left-

\footnotetext{
${ }^{5}$ In order to avoid overlapping of the labels in Figures 8, 9 and 10, we only label selected observations.
} 
hand corner of the plot (low values close to low values), while a number of European countries are located in the upper right-hand corner of the plot (high values close to high values).

The use of standardised variables allows us to compare Moran scatterplots over time, so Figures 8 and 9 are directly comparable. It is immediately apparent that (in contrast with Figure 7) most observations are located in the upper-right and lower-left quadrants, corresponding to high-high and low-low values, respectively. It is also apparent that the spatial distribution of TFP levels is becoming more clustered over time. While in Figure 8 there are two clusters of observations at the two extremes of the spatial distribution (with most other countries scattered in between), in Figure 9 there are four visible clusters of countries with similar values: African countries are clustered in the low-low quadrant, Latin American and Caribbean countries are not clustered in 1960 but are clustered in 2000, and the European countries are clustered in two groups, Northern and Southern Europe.

Another relevant statistic is the local Moran, which gives an indication of spatial clustering of similar values around a particular observation. For a row standardised weights matrix, the global Moran's $I$ equals the mean of the local Moran's $I$ statistics (up to a scaling constant). Since there is a link between the local indicators and the global statistic, local outliers are also associated with the countries that exert the most influence on the global statistic.

Figure 10 is a map showing the countries with significant $(p<0.05)$ values of the local Moran statistic for TFP growth rates. ${ }^{6}$ The colour code on the map indicates the quadrant in the Moran scatterplot to which the countries belong. There are several spatial clusters. The countries of Central America, and a few countries in South America (Venezuela, Bolivia and Paraguay) are at the centre of low-low clusters of TFP growth rates. A similar low-low cluster is to be found in Western Africa. There are pockets of high-high values in Europe (centered in Ireland and Greece) and in East- and South-East Asia.

Figures 11 and 12 reproduce the analysis of Figure 10, but for TFP levels in 1960 and 2000. Recall that the global Moran statistic indicates that TFP levels are more spatially autocorrelated than TFP growth rates. This result is also apparent in Figures 11 and 12. In 1960 high values of TFP are clustered in North America and Europe, while low values are clustered in Sub-Saharan Africa and South and South-East Asia. South Africa is an example of the high-low variety, that is, a high TFP country surrounded by low TFP countries. In 2000 the high-high clusters remain unchanged, but a new low-low cluster has emerged in Western Africa (this is consistent with the finding of a cluster of low TFP growth rates in Western Africa in Figure 10). The low-low clusters in South- and South-East Asia have disappeared.

To summarise, our exploratory analysis shows the presence of spatial clusters of TFP

\footnotetext{
${ }^{6}$ The local Moran is an example of a Local Indicator of Spatial Association (LISA), as defined in Anselin (1995).
} 
growth rates and levels, suggesting that there is a spatial dimension to technology diffusion. In particular, we have seen that clusters of low values can persist over time, indicating that there may be barriers to the adoption of technology. In the next section we explore these results further, by extending a standard model of technology diffusion in ways that incorporate space.

\section{Model Specification}

\subsection{Nelson-Phelps Model}

Nelson and Phelps (1966) argue that simply treating human capital as an input in the production function is misspecifying its role, since education also affects the process of technology diffusion by speeding up the rate at which new inventions are adopted. In their model they make a distinction between the theoretical level of technology, defined as the stock of knowledge or body of techniques available to adopters, and the average level of technology that prevails in practice. The theoretical level of technology is assumed to grow at a constant and exogenous rate:

$$
T_{t}=T_{0} e^{\lambda t}, \quad \lambda>0
$$

where $T_{t}$ is the theoretical level of technology at time $t$, and $\lambda$ is the growth rate of technology. In this sense their model is equivalent to the standard neoclassical model of growth, where the process of knowledge creation is exogenous, and technology is treated as a public good.

The rate at which the theoretical level of technology is turned into improved technology in practice depends on the educational attainment of the adopters, and on the gap between the theoretical level of technology and the level of technology in practice:

$$
\frac{\dot{A}_{t}}{A_{t}}=\Phi(h)\left[\frac{T_{t}-A_{t}}{A_{t}}\right], \quad \Phi(0)=0, \Phi^{\prime}(h)>0,
$$

where $A_{t}$ is the level of technology in practice at time $t$, and $h$ is the level of education (assumed constant over time).

In the long run, the growth rate of technology in practice is equal to the growth rate of theoretical technology, with a constant technology gap. This result holds as long as the level of education remains constant over time. The steady state technology gap is given by:

$$
\frac{A}{T}=\frac{\Phi(h)}{\lambda+\Phi(h)}
$$

If the level of education is allowed to increase over time, the level of technology in practice will approach the theoretical level of technology, and the technology gap will vanish. 
Although the Nelson and Phelps (1966) model was developed to explain technology adoption by individuals and firms, the authors suggest that the model may also be applied to the study of economic growth at a more aggregate level. Benhabib and Spiegel (1994) adapt the Nelson-Phelps model to study the effect of human capital on growth in a cross-country growth-accounting framework. They add an innovation term to the Nelson-Phelps model of equation (7), arguing that in addition to the successful adoption of foreign technology, education also determines a country's capacity to develop new ideas domestically. The growth rate of technology in country $i$ at time $t$ is then given by:

$$
\frac{\dot{A}_{i t}}{A_{i t}}=g\left(h_{i}\right)+c\left(h_{i}\right)\left[\frac{T_{t}-A_{i t}}{A_{i t}}\right] .
$$

Note that the theoretical level of knowledge at time $t$ is equal to $T_{t}$ for all countries. In order to estimate the model, they approximate the theoretical level of knowledge $T_{t}$ by the level of technology of the technology leader, and assume that the level of educational attainment is constant over time (they use the average over the entire period). The level of educational attainment enters the equation in logarithmic form, so that $g\left(h_{i}\right)=c\left(h_{i}\right)=\ln \left(h_{i}\right)$.

Their empirical results are broadly supportive of the Nelson-Phelps model. The logarithm of human capital is found to have a positive impact on productivity growth, both on its own and when interacted with the technology gap. They also show that while the level of human capital is an important determinant of productivity growth, the growth rate of human capital is not. This result provides some evidence against the Lucas (1988) model, where growth is driven by the accumulation of human capital.

We extend the Benhabib and Spiegel (1994) model of equation (9) in two ways. First, we allow the innovation term to depend on both the level and the growth rate of human capital, thus nesting the Nelson and Phelps (1966) and Lucas (1988) approaches. This allows us to test both approaches simultaneously. The distinction between the two models is important because they have different implications for the effectiveness of raising the level of human capital. In the Lucas (1988) model, an increase in the level of human capital results in a one-off increase in the level of output, while in the Nelson and Phelps (1966) model an increase in the level of human capital results in a permanent increase in the growth rate of output. Our nested specification is the following:

$$
\frac{\dot{A}_{i t}}{A_{i t}}=g\left(h_{i t}\right)+c\left(h_{i t}\right)\left[\frac{\max \left(A_{i t}\right)-A_{i t}}{A_{i t}}\right]+\frac{\dot{h}_{i t}}{h_{i t}},
$$

where the last term corresponds to the Lucas (1988) approach. Following Benhabib and Spiegel (1994), we approximate the level of theoretical knowledge by the maximum level of TFP at time $t$, and assume that human capital enters the equation in logarithmic form. ${ }^{7}$

\footnotetext{
${ }^{7}$ In our nested model a steady state is only possible if the level of human capital is constant over time,
} 
Second, we consider two types of econometric model to deal with the presence of spatial dependence in TFP growth rates: the spatial autoregressive (or spatial lag) model, and the spatial error model.

\subsection{Spatial Lag Model}

In the spatial lag model we allow the growth rate of technology in country $i$ to depend on a weighted average of the technology growth rates of its neighbours, in addition to the explanatory variables of the Nelson-Phelps model. The model in equation (10) becomes: ${ }^{8}$

$$
\frac{\dot{A}}{A}=\alpha+\mathbf{x} \boldsymbol{\beta}+\rho W \frac{\dot{A}}{A}+\mu, \quad \mu \sim N\left(0, \sigma^{2} I\right)
$$

where $\mathbf{x}$ is a vector of explanatory variables, and $\rho$ is a parameter indicating the extent of the spatial interaction between observations with non-zero entries in $W$, the spatial weights matrix.

Note that this implies that the growth rate of technology in each country depends not only on the values of the explanatory variables in that country, but also on the values of the explanatory variables in other countries, subject to distance decay. This can be seen by expressing the model in reduced form:

$$
\begin{aligned}
(I-\rho W) \frac{\dot{A}}{A} & =\alpha+\mathbf{x} \boldsymbol{\beta}+\mu \\
\frac{\dot{A}}{A} & =(I-\rho W)^{-1}[\alpha+\mathbf{x} \boldsymbol{\beta}+\mu] .
\end{aligned}
$$

For example, a marginal increase in schooling in country $i$ has a direct effect on the growth rate of technology in that country, and an indirect effect on the growth rate of technology of its neighbours. In addition, the original direct and indirect effects result in induced effects in the neighbours of the neighbours of country $i$, and in turn in the neighbours of those neighbours, and so on throughout the whole system, including some feedback effects on country $i$ itself. The total effect of a marginal increase in schooling is therefore equal to the sum of the direct, indirect and induced effects, and its magnitude differs across countries. By estimating the spatial lag model we are able to show the impact on world technology growth of a marginal increase in schooling in country $i$, and to compare the total effects for different countries. ${ }^{9}$

so that the growth rate of human capital is zero. This may be a reasonable assumption if we take a narrow view of education and consider only the average years of schooling of the population. Since there is a limit to the number of years a person can spend in the education system, the growth rate of schooling will tend to zero in the long run.

${ }^{8}$ For simplicity we drop the subscript $i$ in all subsequent equations.

${ }^{9}$ For a discussion on spatial spillovers and spatial externalities see Anselin (2003). 
Estimation of equation (11) by OLS results in biased and inconsistent estimates, because the spatially-lagged dependent variable on the right hand side of equation (11) is correlated with the error term. Instead, the model can be estimated using instrumental variables or maximum likelihood (Anselin, 1988). Maximum likelihood estimation requires that the errors are normally distributed, while instrumental variables estimation does not. ${ }^{10}$ Since normality cannot be rejected for the regression residuals in our standard models (discussed in Section 5.1), we use maximum likelihood to estimate the model in equation (11).

\subsection{Spatial Error Model}

In the spatial error model the spatial dependence is restricted to the error term. Intuitively, we can think of the spatial dependence working through omitted variables with a spatial dimension (climate, social norms, exogenous shocks), so that the errors from different countries are spatially correlated. Equation (10) becomes:

$$
\frac{\dot{A}}{A}=\alpha+\mathbf{x} \boldsymbol{\beta}+\varepsilon, \quad \varepsilon=\lambda W \varepsilon+\mu ; \quad \mu \sim N\left(0, \sigma^{2} I\right),
$$

where $\lambda$ is a parameter indicating the extent of the spatial correlation between the errors. Note that since $\varepsilon=(I-\lambda W)^{-1} \mu$, the model can be rewritten as follows (compare with equation (13)):

$$
\frac{\dot{A}}{A}=\alpha+\mathbf{x} \boldsymbol{\beta}+(I-\lambda W)^{-1} \mu .
$$

Estimation of this model using OLS results in unbiased but inefficient estimates. It should therefore be estimated using maximum likelihood or general method of moments (Anselin, 1988). ${ }^{11}$

\section{Empirical Findings}

\subsection{Standard Models}

We start by estimating the standard Nelson-Phelps model of Benhabib and Spiegel (1994) given in equation (9). It has been suggested in the literature (Benhabib and Spiegel, 2002 and Engelbrecht, 2003) that the level of schooling in 1960 may not adequately reflect the amount

\footnotetext{
${ }^{10}$ In the case of instrumental variables, Kelejian and Robinson (1993) have shown that the proper set of instruments to be used are the exogenous explanatory variables $\mathbf{x}$ and the spatially lagged exogenous variables $\mathbf{W x}$.

${ }^{11}$ By rearranging equation (15) it can be shown that the spatial error model is equivalent to an extended version of the spatial lag model that includes both a spatially lagged dependent variable and the set of spatially lagged independent variables (excluding the constant term). This equivalence only holds if a number of non-linear constraints are satisfied. The resulting model is known as the 'spatial Durbin' or 'common factor' model (Anselin, 2001).
} 
of human capital available for innovation over the period 1960-2000, since a significant number of countries experienced rapid schooling growth in the 1960s and 1970s. We therefore estimate the model in equation (9) using two different measures of the human capital stock: average years of schooling in the population aged 25 and over in 1960, and the average of this measure over the entire period 1960-2000.

In Column (1) of Table 3 we present estimates of the standard Nelson-Phelps model using the average years of schooling in 1960 as a measure of the human capital stock. The coefficient of the Nelson-Phelps term is positive as expected, indicating the presence of a technology catch-up effect. Countries that lagged behind the technology leader in 1960 experienced rapid productivity growth, given their levels of human capital. The effect of initial schooling on productivity growth is also positive, although fairly small and not statistically significant at the $5 \%$ level. A $1 \%$ increase in the average years of schooling in 1960 is associated with a $0.08 \%$ increase in TFP growth over the period 1960-2000.

Column (2) shows the results using average schooling over the period 1960-2000 as the measure of human capital. The coefficient of the Nelson-Phelps term is again positive and highly significant, and also larger than in column (1). The coefficient of schooling is positive, but now also highly significant. The size of the effect of schooling on productivity growth is larger, so that a $1 \%$ increase in the average years of schooling over 1960-2000 results in an extra $0.5 \%$ growth in TFP over the period. Our results confirm those of Benhabib and Spiegel (2002), who also find that using the average years of schooling over the whole period results in larger coefficients for schooling and the Nelson-Phelps term. The fit of the model in column (2) is also an improvement over that in column (1), as indicated by the higher values of the adjusted $R$-squared and the $F$-statistic. These results support our hypothesis that the average years of schooling over the period 1960-2000 are a better measure of the human capital stock than the average years of schooling in 1960, although we cannot rule out the possibility that the average years of schooling may be affected by the productivity growth rate, resulting in endogeneity bias.

Column (3) shows the results of estimating model (10) with $g(h)=0$, so that domestic innovation is a function of human capital accumulation, as in the Lucas approach. The coefficient of the Nelson-Phelps term remains positive and highly significant, and has a larger value than in columns (1) and (2). The coefficient of schooling growth is also positive and significant at the $5 \%$ level. Roughly, an increase of $1 \%$ in the growth rate of schooling results in a $0.3 \%$ increase in the growth rate of TFP.

Column (4) presents estimates of the nested model of equation (10). Our aim with this specification is to test the relative merits of the Nelson and Phelps (1966) and Lucas (1988) approaches. We find that both the growth rate of human capital and its level have a positive and statistically significant impact on the growth rate of productivity. Interestingly, both coefficients are larger and more significant in the nested model than in the models where 
they appear on their own. A 1\% increase in the average years of schooling in 1960 raises the TFP growth rate by $0.8 \%$, while a $1 \%$ increase in the growth rate of schooling raises the TFP growth rate by $0.6 \%$. A possible explanation is that since the growth rate and level of schooling are negatively correlated, and since both are positively correlated with TFP growth, omitting one or the other results in a downward bias in the remaining coefficient. It would seem that neither the Nelson and Phelps (1966) model nor the Lucas (1988) model can fully explain the growth rate of TFP over the period 1960-2000.

Turning to the regression diagnostics, the Jarque-Bera (1987) statistic does not reject normality for any of the models in Table 3, ensuring the validity of the spatial tests discussed below, and of the maximum likelihood estimation method used in column (5). The White (1980) test for generic heteroscedasticity does not reject the null hypothesis of homoscedasticity for any of the models, but the Breusch-Pagan (1979) test is significant at $5 \%$ in columns (1) and (4). Anselin and Griffith (1988) show that the power of the tests for spatial dependence is reduced in the presence of heteroscedasticity and vice-versa, so that the diagnostics for columns (1) and (4) must be interpreted with caution. However, we find that the spatially adjusted Breush-Pagan statistic is no longer significant after estimating the spatial lag model of equation (11).

\subsection{Spatial Diagnostics and the Spatial Lag Model}

Spatial diagnostics are provided at the end of each column in Table 3. We report five tests for spatial dependence: the Moran's I test, two Lagrange Multiplier tests for spatial error and spatial lag dependence, and two robust Lagrange Multiplier tests for spatial error and spatial lag dependence that are robust to the local presence of the other form of spatial dependence.

The first statistic reported is the Moran's I statistic for regression residuals (Cliff and Ord, 1981). This test is for the general presence of spatial dependence, and does not allow us to discriminate between the spatial error and spatial lag models. The statistic is significant at the $1 \%$ level for all the standard regressions in Table 3, indicating that the residuals from the OLS regressions are spatially autocorrelated and that the standard models are misspecified.

In order to discriminate between the two forms of spatial dependence outlined in Section 4, we follow the decision rule suggested by Anselin and Florax (1995) and consider the Lagrange Multiplier (LM) tests for spatial error and spatial lag dependence and their robust counterparts. The LM test statistics for spatial error autocorrelation are significant at the $1 \%$ level for all the standard regressions in Table 3 , as are the LM statistics for an erroneously omitted spatial lag. The robust LM statistics are not significant, except for the model in column (1), where the robust LM statistic for spatial error is significant while the robust 
LM statistic for spatial lag is not.

In what follows we focus on the model in column (4), our nested specification. We have chosen this model for two reasons: (i) because it allows us to test between the Nelson and Phelps (1966) and Lucas (1988) approaches, and (ii) our previous results indicate the possibility of omitted variable bias if either the growth rate or the level of schooling is excluded from the regression.

For the model in column (4), the LM test statistic for an omitted spatial lag is larger than that for spatially autocorrelated errors, indicating that the spatial lag model is more appropriate. The robust LM statistics are not significant, although the robust test for spatial lag dependence is larger than the robust test for spatial error dependence. We therefore proceed to estimate the spatial lag model of equation (11). Intuitively, we are allowing the growth rate of technology to depend not only on the value of domestic explanatory variables (such as the level of schooling, the technology gap and the growth rate of schooling), but also on the growth rate of technology in neighbouring countries. This model also implies that the values of the explanatory variables in other countries have an impact on domestic technology growth. The level of schooling in other countries can affect domestic technology growth via migration or increased contacts between researchers, and the size of the technology gap in neighbouring countries can have an impact by encouraging openness to foreign technology. Under this interpretation, spatial dependence also works through the error term, so that shocks in one country affect the growth rates of other countries.

Column (5) of Table 3 shows the estimation results for the spatial lag model of equation (11). The estimate of the spatial lag parameter is large and highly significant, highlighting the importance of spatial interaction in the model. The positive sign of the estimate indicates that being located close to other countries with high technology growth rates results in higher domestic technology growth, all other things being equal. As with the OLS regression in column (4), the coefficients of both the level and the growth rate of schooling are positive and highly significant, although their values have dropped slightly. Note that the estimated coefficients in the spatial lag model measure only the direct effects of a marginal increase in the explanatory variables on TFP growth. The total effects include the direct, indirect and induced effects discussed in Section 4.2, and are location specific. Figure 13 shows the distribution of the total effects of an increase in the average years of schooling in 1960. Our results indicate that the countries with the most impact on TFP growth are those in Central America, Europe and Southern Africa.

Several additional test statistics are provided for the spatial lag model. The spatially adjusted Breusch-Pagan statistic (Anselin, 1988) is not significant, indicating that the heteroscedasticity present in the OLS regression has been accounted for. The Likelihood Ratio test for spatial lag dependence is significant at the $1 \%$ level, indicating that the spatial lag model provides a better fit than the standard regression model with the same set of explana- 
tory variables. The Lagrange Multiplier test for any remaining spatial error dependence is not significant, indicating that accounting for the spatial lag of the dependent variable is indeed sufficient.

To summarise, we have estimated the Nelson and Phelps (1966) model of technology diffusion, in its original form and with some variations. Our results indicate that both the level and the growth rate of human capital have a positive effect on TFP growth rates. The technology catch-up term is also positive, so that countries that are further behind the technology leader experience higher TFP growth, given their stock of human capital. Moreover, we find that the regression residuals of the standard model are spatially autocorrelated, and that a spatial lag model is more appropriate.

We estimate a spatial lag model of technology diffusion that includes human capital in both levels and growth rates, thus nesting the Nelson and Phelps (1966) and Lucas (1988) approaches. Our results indicate that both the level and growth rate of human capital have a positive impact on TFP growth rates, although the coefficients are slightly smaller than those of the standard regression. The spatial lag parameter (measuring the extent of the spatial dependence in the model) is positive and highly significant, indicating that a country surrounded by high-growth neighbours will experience higher TFP growth, all other things being equal. These results confirm the findings of our exploratory analysis of Section 3.

\section{Conclusions}

In this paper we have investigated the question of whether technology diffusion has a spatial dimension. Previous studies at both the regional and country level have shown that location matters for the diffusion of technology, through increased trade links, foreign direct investment and contacts between researchers. We have argued that the techniques developed in spatial econometrics can be used to analyse the spatial aspects of technology diffusion, to detect clusters and to present them visually, to test for the presence of various forms of spatial dependence, and to estimate models that incorporate space explicitly.

Following Keller (2001), Benhabib and Spiegel (2002) and others, we use total factor productivity (TFP) as a measure of aggregate technology. Our sample covers 73 countries over the period 1960-2000.

Our exploratory analysis shows that TFP growth rates and levels are positively autocorrelated over space, meaning that high or low values tend to be clustered in space. In particular, we have found statistically significant clusters of low TFP values in Sub-Saharan Africa, Central and South America, and clusters of high values in North America and Europe. A cluster of low values was found in South- and South East Asia in 1960, but it is no longer statistically significant in 2000. In addition, we find that TFP levels are more spatially autocorrelated than TFP growth rates, and have become more clustered over time. 
These results suggest the presence of barriers to technology adoption, and the possibility that technology levels are converging locally, with countries forming spatial convergence clubs. As a policy implication, our results suggest that countries would benefit from closer ties to the local technology leader.

We estimate the Nelson and Phelps (1966) model of technology diffusion, while allowing the innovation term to depend on both the level and the growth rate of human capital. Our aim is to test the Nelson and Phelps (1966) and Lucas (1988) approaches. Our results indicate that both the level and the growth rate of human capital have a large and positive impact on TFP growth rates. The technology catch-up term is also positive, indicating that countries that lag behind in terms of technology experience faster TFP growth rates, all other things being equal. It has been suggested in the literature that the Nelson and Phelps (1966) and Lucas (1988) approaches could refer to different forms of human capital, with the former more concerned with the level of tertiary and specialised schooling and the latter with the improvement of basic skills, such as literacy and primary education. This is an interesting possibility that could be explored further.

We also find that the regression residuals of the model are spatially autocorrelated, indicating the presence of spatial dependence. We conclude that the spatial patterns found in the exploratory analysis persist even after human capital, absorptive capacity and technological catch-up have been accounted for, and that the standard model is misspecified. Spatial dependence tests indicate that a spatial lag model is more appropriate. In this model we assume that the growth rate of technology in a country is affected by the technology growth rates in other countries located close to it. We are thus able to investigate whether distance has an impact on technology diffusion, without restricting our analysis to one or several specific channels of diffusion.

Our results indicate that both the level and growth rate of human capital have a positive impact on TFP growth, even after controlling for the spatial dependence effect. The impact of being located close to a country with high TFP growth rates is positive and substantial, confirming our hypothesis that knowledge spillovers between countries have a spatial dimension. For future research it might be interesting to explore whether other measures of distance (such as travel costs and cultural distance) yield similar results.

\section{Acknowledgements}

We thank Jan Willem Gunning, Miguel Portela and participants at the Tinbergen Institute seminars for their helpful comments. 


\section{References}

Acs, Z. \& A. Varga (2002), 'Geography, endogenous growth and innovation', International Regional Science Review 26(2), 153-66.

Anselin, L. (1988), Spatial Econometrics: Methods and Models, Kluwer, Dordrecht.

Anselin, L. (1995), 'Local indicators of spatial association - LISA', Geographical Analysis $\mathbf{2 7}(2), 93-115$.

Anselin, L. (1996), The Moran scatterplot as an ESDA tool to assess local instability in spatial association, in M.Fisher, H.Scholten \& D.Unwin, eds, 'Spatial Analytical Perspectives on GIS', Taylor \& Francis, London.

Anselin, L. (2001), Spatial econometrics, in B.Baltagi, ed., 'A Companion to Theoretical Econometrics', Basil Blackwell, Oxford, pp. 310-330.

Anselin, L. (2003), 'Spatial externalities, spatial multipliers and spatial econometrics', International Regional Science Review 26(2), 153-66.

Anselin, L. \& D. Griffith (1988), 'Do spatial effects really matter in regression analysis?', Papers in Regional Science 74, 143-52.

Anselin, L. \& R. Florax (1995), Small sample properties of tests for spatial dependence in regression models, in L.Anselin \& R.Florax, eds, 'New Directions in Spatial Econometrics', Springer, Berlin, pp. 21-74.

Barro, R. \& J. Lee (2001), 'International data on educational attainment: Updates and implications', Oxford Economic Papers 3, 541-63.

Barro, R. \& X. Sala-i Martin (1995), Economic Growth, McGraw-Hill, New York.

Benhabib, J. \& M. Spiegel (1994), 'The role of human capital in economic development: Evidence from aggregate cross-country data', Journal of Monetary Economics 34, 143173.

Benhabib, J. \& M. Spiegel (2002), 'Human capital and technology diffusion', Working Papers in Applied Economic Theory, Federal Reserve Bank of San Francisco, San Francisco, CA.

Breusch, T. \& A. Pagan (1979), 'A simple test for heteroskedasticity and random coefficient variation', Econometrica 47, 1287-94.

Cliff, A. \& J. Ord (1981), Spatial Processes: Models and Applications, Pion, London.

Coe, D. \& E. Helpman (1995), 'International R\&D spillovers', European Economic Review 39, 859-87.

Cohen, W. \& D. Levinthal (1989), 'Innovation and learning: The two faces of R\&D', Economic Journal 99, 569-96.

Easterly, W. \& R. Levine (2002), 'It's not factor accumulation: Stylized facts and growth models', Working Papers No. 164, Central Bank of Chile, Santiago, Chile. 
Eaton, J. \& S. Kortum (1996), 'Trade in ideas: Patenting and productivity in the OECD', Journal of International Economics 40, 251-78.

Engelbrecht, H. (2003), 'Human capital and economic growth: Cross-section evidence for OECD countries', Economic Record 79, 40-51.

Feldman, M. \& F. Lichtenberg (1997), 'The impact and organization of publicly-funded R\&D in the european community', NBER Working Papers No. 6040, Cambridge, MA.

Fingleton, B. (1999), 'Estimates of time to economic convergence: An analysis of regions of the European Union', International Regional Science Review 22, 5-35.

Florax, R. \& P. Nijkamp (2004), Misspecification in linear spatial regression models, in K.Kempf-Leonard, ed., 'Encyclopedia of Social Measurement', Academic Press, San Diego.

Fraumeni, B. (1997), 'The measurement of depreciation in the US national income and product accounts', Survey of Current Business 77(7), 7-23.

Gollin, D. (2002), 'Getting income shares right', Journal of Political Economy 110, 458-74.

Griffith, R., S. Redding \& J. Van Reenen (2000), 'Mapping the two faces of R\&D: Productivity growth in a panel of OECD industries', Working Papers No. 2002/2, Institute for Fiscal Studies, London.

Jaffe, A. \& M. Trajtenberg (1999), 'International knowledge flows: Evidence from patent citations.', Economics of Innovation and New Technology 8(1/2), 105-136.

Jarque, C. \& A. Bera (1987), 'A test for normality of observations and regression residuals', International Statistical Review 55, 163-72.

Kelejian, H. \& D. Robinson (1993), 'A suggested method of estimation for spatial interdependent models with autocorrelated errors, and an application to a county expenditure model', Papers in Regional Science 72, 297-312.

Keller, W. (1998), 'Are international R\&D spillovers trade related? Analyzing spillovers among randomly matched trade partners', European Economic Review 42, 1469-81.

Keller, W. (2001), 'The geography and channels of diffusion at the world's technology frontier', NBER Working Papers No. 8150, Cambridge, MA.

Keller, W. (2002), 'International technology diffusion', CEPR Discussion Paper No. 3133, London.

Le Gallo, J., C. Ertur \& C. Baumont (2003), A spatial econometric analysis of convergence across European regions, 1980-1995, in B.Fingleton, ed., 'European Regional Growth', Springer, Berlin.

López-Bazo, E., E. Vayá, A. Mora \& J. Suriñach (1999), 'Regional economic dynamics and convergence in the European Union', Annals of Regional Science 33, 343-70.

Lucas, R. (1988), 'On the mechanics of economic development', Journal of Monetary Economics 22, 3-24. 
Mankiw, N., D. Romer \& D. Weil (1992), 'A contribution to the empirics of economic growth', Quarterly Journal of Economics 107(2), 407-437.

Moreno, R. \& B. Trehan (1997), 'Location and the growth of nations', Journal of Economic Growth 2(4), 399-418.

Mossi, M., P. Aroca, I. Fernandez \& C. Azzoni (2003), 'Growth dynamics and space in Brazil', International Regional Science Review 26, 393-418.

Nelson, R. \& E. Phelps (1966), 'Investment in humans, technological diffusion, and economic growth', American Economic Review 56(1/2), 65-75.

Oulton, N. \& S. Srinivasan (2003), 'Capital stocks, capital services, and depreciation: An integrated framework', Bank of England Working Papers No. 192, London.

Parente, S. \& E. Prescott (2000), Barriers to Riches, MIT Press, Cambridge, MA.

Polanyi, M. (1958), Personal Knowledge: Towards a Post-Critical Philosophy, University of Chicago Press, Chicago.

Ramírez, M. \& A. Loboguerrero (2002), 'Spatial dependence and economic growth: Evidence from a panel of countries', Borradores de Economía No. 206, Central Bank of Colombia, Bogotá.

Rey, S. \& B. Montouri (1999), 'US regional income convergence: A spatial econometric perspective', Regional Studies 33(2), 143-56.

Scarpetta, S., A. Bassanini, D. Pilat \& P. Schereyer (2000), 'Economic growth in the OECD area: Recent trends at the aggregate and sectoral level', OECD Economics Department Working Papers No. 248, Paris.

Whelan, K. (2002), 'Computers, obsolescence, and productivity', Review of Economics and Statistics 84(3), 445-461.

White, H. (1980), 'A heteroskedastic-consistent covariance matrix estimator and a direct test for heteroskedasticity', Econometrica 48, 817-38.

Xu, B. (2000), 'Multinational enterprises, technology diffusion, and host country productivity growth', Journal of Development Economics 62, 477-493.

Xu, B. \& J. Wang (1999), 'Capital goods trade and R\&D spillovers in the OECD', Canadian Journal of Economics 32, 1258-74.

\section{A Tables and Figures}

Table 1: Total Factor Productivity Estimates

\begin{tabular}{lccc}
\hline Country & ISO code & $\begin{array}{c}\text { Avg. annual growth of } \\
\text { TFP }(1960-2000)\end{array}$ & $\ln ($ TFP $)$ in 1960 \\
\hline Argentina & ARG & 0.569 & 6.351 \\
\hline
\end{tabular}


Table 1: (continued)

\begin{tabular}{|c|c|c|c|}
\hline Country & ISO code & $\begin{array}{l}\text { Avg. annual growth of } \\
\text { TFP (1960-2000) }\end{array}$ & $\ln (\mathrm{TFP})$ in 1960 \\
\hline Australia & AUS & 1.233 & 6.457 \\
\hline Austria & AUT & 2.060 & 6.066 \\
\hline Bangladesh & BGD & 1.155 & 5.423 \\
\hline Barbados & $\mathrm{BRB}$ & 3.197 & 5.694 \\
\hline Belgium & BEL & 1.895 & 6.236 \\
\hline Bolivia & BOL & 0.162 & 5.805 \\
\hline Brazil & BRA & 1.687 & 5.699 \\
\hline Cameroon & CMR & -0.458 & 5.829 \\
\hline Canada & CAN & 0.862 & 6.607 \\
\hline Chile & CHL & 1.469 & 5.992 \\
\hline Colombia & $\mathrm{COL}$ & 0.446 & 5.990 \\
\hline Costa Rica & CRI & 0.090 & 6.240 \\
\hline Denmark & DNK & 1.380 & 6.370 \\
\hline Dominican Rep. & DOM & 1.274 & 5.927 \\
\hline Ecuador & $\mathrm{ECU}$ & 1.064 & 5.557 \\
\hline El Salvador & SLV & 0.273 & 6.299 \\
\hline Finland & FIN & 2.083 & 6.068 \\
\hline France & FRA & 1.694 & 6.204 \\
\hline Ghana & GHA & 1.597 & 4.785 \\
\hline Greece & GRC & 2.414 & 5.720 \\
\hline Guatemala & GTM & 0.893 & 6.050 \\
\hline Honduras & HND & -0.265 & 5.793 \\
\hline Hong Kong & $\mathrm{HKG}$ & 4.039 & 5.348 \\
\hline Iceland & ISL & 1.464 & 6.258 \\
\hline India & IND & 1.988 & 5.021 \\
\hline Indonesia & IDN & 1.173 & 5.453 \\
\hline Iran & IRN & 1.171 & 5.963 \\
\hline Ireland & IRL & 2.698 & 6.173 \\
\hline Israel & ISR & 2.015 & 6.017 \\
\hline Italy & ITA & 2.289 & 6.045 \\
\hline Jamaica & JAM & 0.199 & 5.587 \\
\hline Japan & JPN & 2.669 & 5.564 \\
\hline Jordan & JOR & 0.452 & 6.118 \\
\hline Kenya & KEN & 0.690 & 4.979 \\
\hline Lesotho & LSO & -0.429 & 5.254 \\
\hline Malawi & MWI & 1.438 & 4.522 \\
\hline Malaysia & MYS & 2.159 & 5.724 \\
\hline Mali & MLI & -0.874 & 5.547 \\
\hline Mauritius & MUS & 2.937 & 5.693 \\
\hline Mexico & MEX & 0.953 & 6.158 \\
\hline Mozambique & MOZ & -1.059 & 5.877 \\
\hline Nepal & NPL & 0.228 & 5.241 \\
\hline Netherlands & NLD & 1.298 & 6.441 \\
\hline
\end{tabular}


Table 1: (continued)

\begin{tabular}{lccc}
\hline Country & ISO code & $\begin{array}{c}\text { Avg. annual growth of } \\
\text { TFP }(1960-2000)\end{array}$ & \\
\hline New Zealand & NZL & 0.338 & 6.636 \\
Nicaragua & NIC & -1.386 & 6.120 \\
Niger & NER & -0.691 & 5.461 \\
Norway & NOR & 1.735 & 6.209 \\
Panama & PAK & 2.581 & 4.875 \\
Pakistan & PAN & 1.194 & 5.707 \\
Paraguay & PRY & -0.128 & 6.144 \\
Peru & PER & 0.383 & 5.757 \\
Philippines & PHL & 0.596 & 5.653 \\
Portugal & PRT & 2.319 & 5.770 \\
Senegal & SEN & -0.340 & 5.682 \\
South Africa & ZAF & 0.877 & 6.308 \\
South Korea & KOR & 2.812 & 5.551 \\
Spain & ESP & 2.318 & 5.899 \\
Sri Lanka & LKA & 0.703 & 5.625 \\
Sweden & SWE & 1.326 & 6.342 \\
Switzerland & CHE & 0.721 & 6.506 \\
Syria & SYR & 2.126 & 5.629 \\
Thailand & THA & 2.717 & 4.873 \\
Togo & TGO & -0.393 & 5.249 \\
Trinidad \& Tobago & TTO & 1.269 & 6.279 \\
Turkey & TUR & 1.280 & 5.714 \\
Uganda & UGA & 0.243 & 5.416 \\
United Kingdom & GBR & 1.252 & 6.405 \\
United States & USA & 1.049 & 6.721 \\
Uruguay & URY & 0.525 & 6.349 \\
Venezuela & VEN & -0.785 & 6.642 \\
Zambia & ZMB & -0.163 & 5.182 \\
Zimbabwe & ZWE & 1.727 & 4.487 \\
\hline
\end{tabular}

Table 2: Moran's I Statistics

\begin{tabular}{lccc}
\hline & Moran's I & Standard Deviation & Probability \\
\hline TFP growth (1960-2000) & 0.1675 & 0.0351 & 0.0000 \\
$\ln$ (TFP) in 1960 & 0.2808 & 0.0351 & 0.0000 \\
$\ln$ (TFP) in 2000 & 0.2975 & 0.0351 & 0.0000 \\
\hline
\end{tabular}


Table 3: Different specifications for models of TFP growth (1960-2000)

\begin{tabular}{|c|c|c|c|c|c|}
\hline & (1) & $(2)$ & $(3)$ & (4) & $(5)$ \\
\hline Constant & $\begin{array}{c}0.780^{* *} \\
(0.161)\end{array}$ & $\begin{array}{c}-0.269 \\
(0.228)\end{array}$ & $\begin{array}{c}0.193 \\
(0.319)\end{array}$ & $\begin{array}{c}-1.210^{*} \\
(0.523)\end{array}$ & $\begin{array}{c}-1.366^{* *} \\
(0.497)\end{array}$ \\
\hline Nelson-Phelps term & $\begin{array}{c}2.588^{* *} \\
(0.982)\end{array}$ & $\begin{array}{c}3.775^{* *} \\
(0.756)\end{array}$ & $\begin{array}{c}4.288^{* *} \\
(0.885)\end{array}$ & $\begin{array}{c}3.123^{* *} \\
(0.903)\end{array}$ & $\begin{array}{c}3.226^{* *} \\
(0.828)\end{array}$ \\
\hline $\ln$ (schooling) in 1960 & $\begin{array}{c}0.082 \\
(0.176)\end{array}$ & & & $\begin{array}{c}0.777^{* *} \\
(0.238)\end{array}$ & $\begin{array}{c}0.577^{* *} \\
(0.223)\end{array}$ \\
\hline $\ln ($ schooling $)$ average 1960-2000 & & $\begin{array}{c}0.473^{* *} \\
(0.148)\end{array}$ & & & \\
\hline Schooling growth (1960-2000) & & & $\begin{array}{c}0.251^{*} \\
(0.117)\end{array}$ & $\begin{array}{c}0.642^{* *} \\
(0.162)\end{array}$ & $\begin{array}{c}0.515^{* *} \\
(0.150)\end{array}$ \\
\hline $\mathrm{W}^{*} \mathrm{TFP}$ growth (spatial lag) & & & & & $\begin{array}{c}0.534^{* *} \\
(0.201)\end{array}$ \\
\hline Observations & 73 & 73 & 73 & 73 & 73 \\
\hline$F$ statistic & $10.58^{* *}$ & $26.68^{* *}$ & $13.44^{* *}$ & $13.76^{* *}$ & \\
\hline adj. $R$-squared & 0.21 & 0.42 & 0.26 & 0.35 & \\
\hline Jarque-Bera & 0.14 & 1.21 & 0.90 & 0.97 & \\
\hline Breusch-Pagan / Spatial B-P & $8.24^{*}$ & 5.16 & 0.43 & $7.61^{*}$ & 7.17 \\
\hline White & 10.85 & 7.91 & 4.58 & 12.94 & \\
\hline Moran's $I$ (error) & $6.71^{* *}$ & $5.47^{* *}$ & $6.56^{* *}$ & $4.60^{* *}$ & \\
\hline LM (error) & $27.60^{* *}$ & $17.20^{* *}$ & $26.32^{* *}$ & $11.22^{* *}$ & 0.01 \\
\hline Robust LM (error) & $5.17^{*}$ & 0.48 & 3.66 & 0.09 & \\
\hline LM (lag) & $22.95^{* *}$ & $19.46^{* *}$ & $22.66^{* *}$ & $13.11^{* *}$ & \\
\hline Robust LM (lag) & 0.52 & 2.74 & 0.00 & 1.99 & \\
\hline Likelihood ratio (lag) & & & & & $6.95^{* *}$ \\
\hline
\end{tabular}


Figure 1: Scatterplot of TFP growth (1960-2000) against $\ln ($ TFP) in 1960

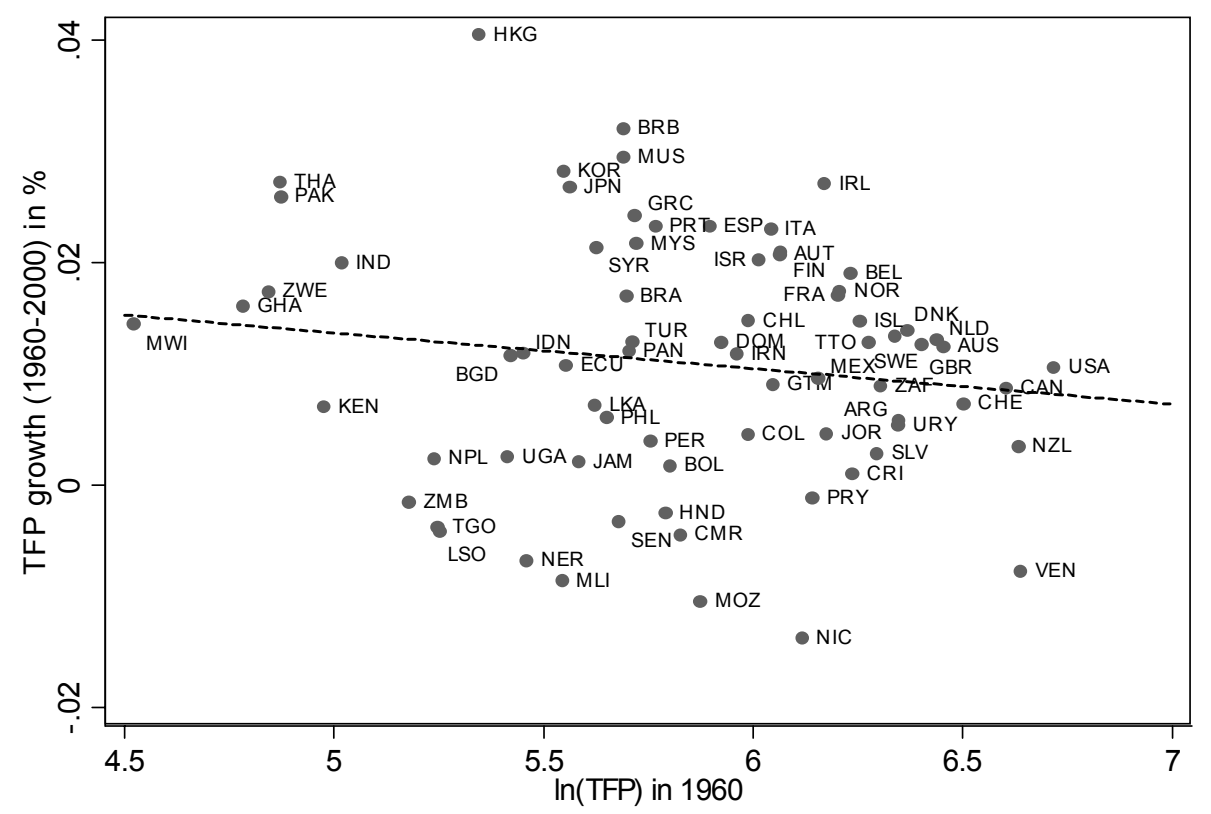


Figure 2: Scatterplot of TFP growth (1960-2000) against $\ln ($ schooling) in 1960

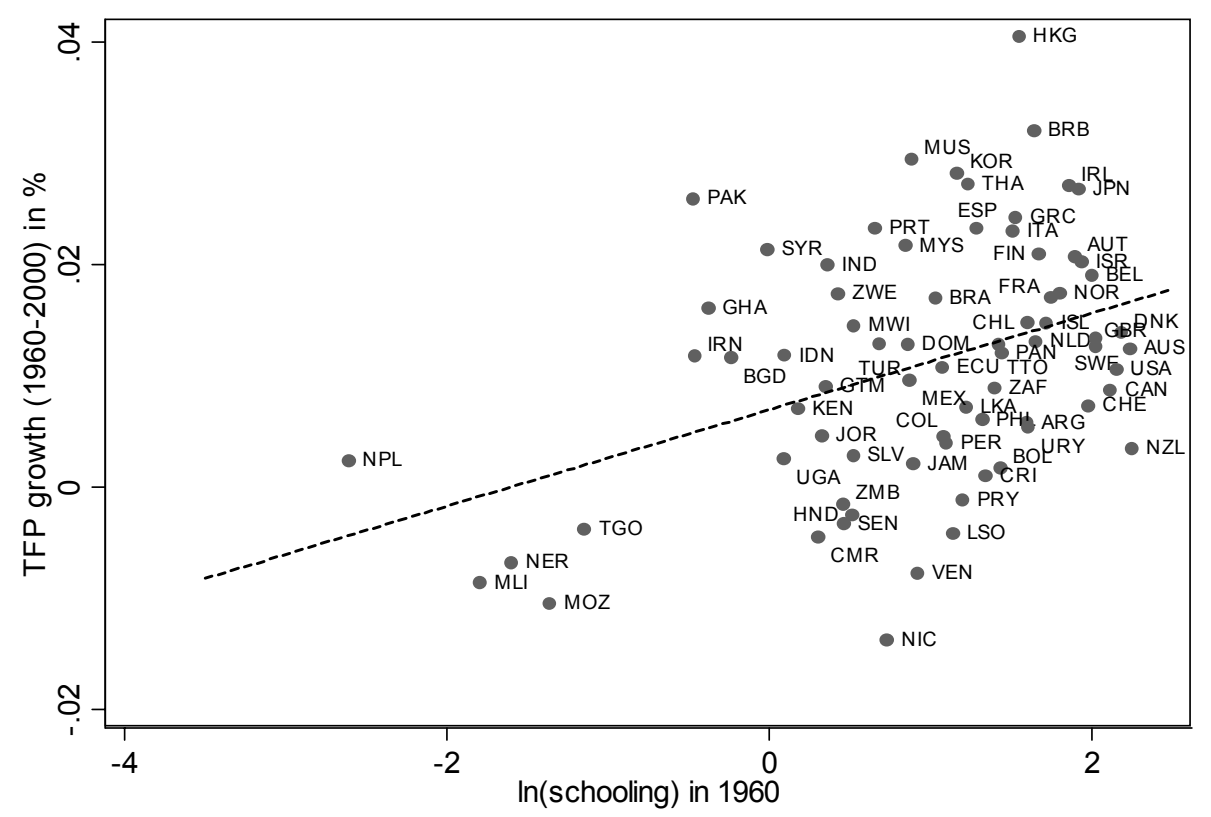

Figure 3: Distribution of TFP growth rates (1960-2000) in \%

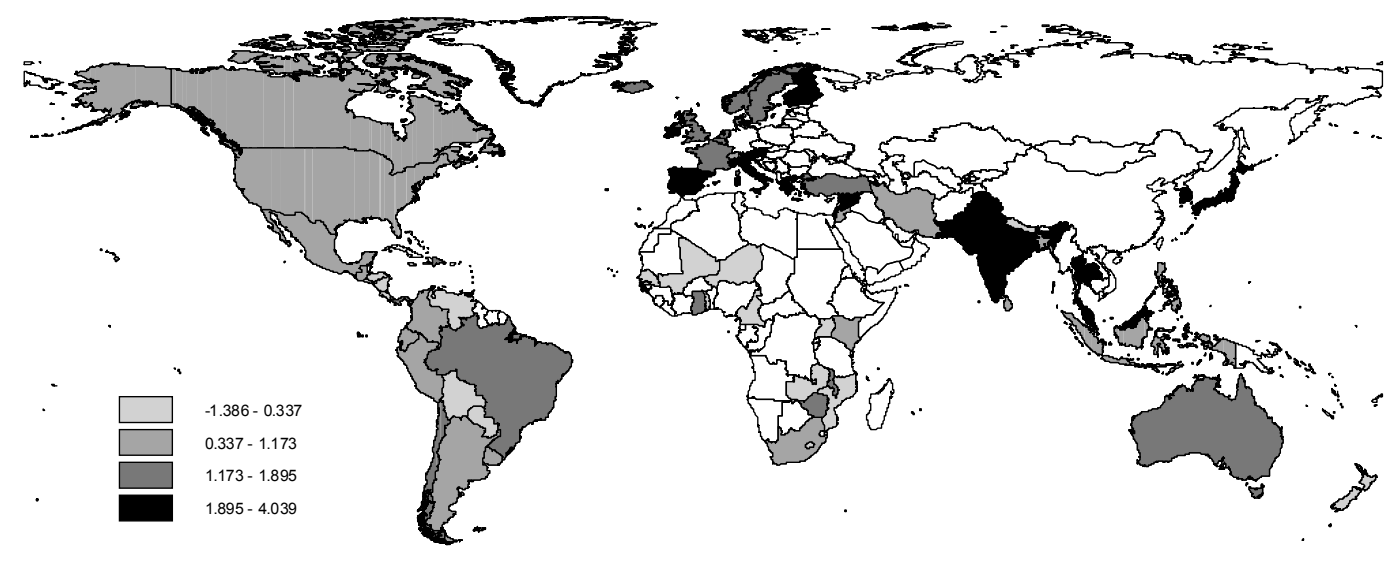


Figure 4: Distribution of $\ln (\mathrm{TFP})$ in 1960

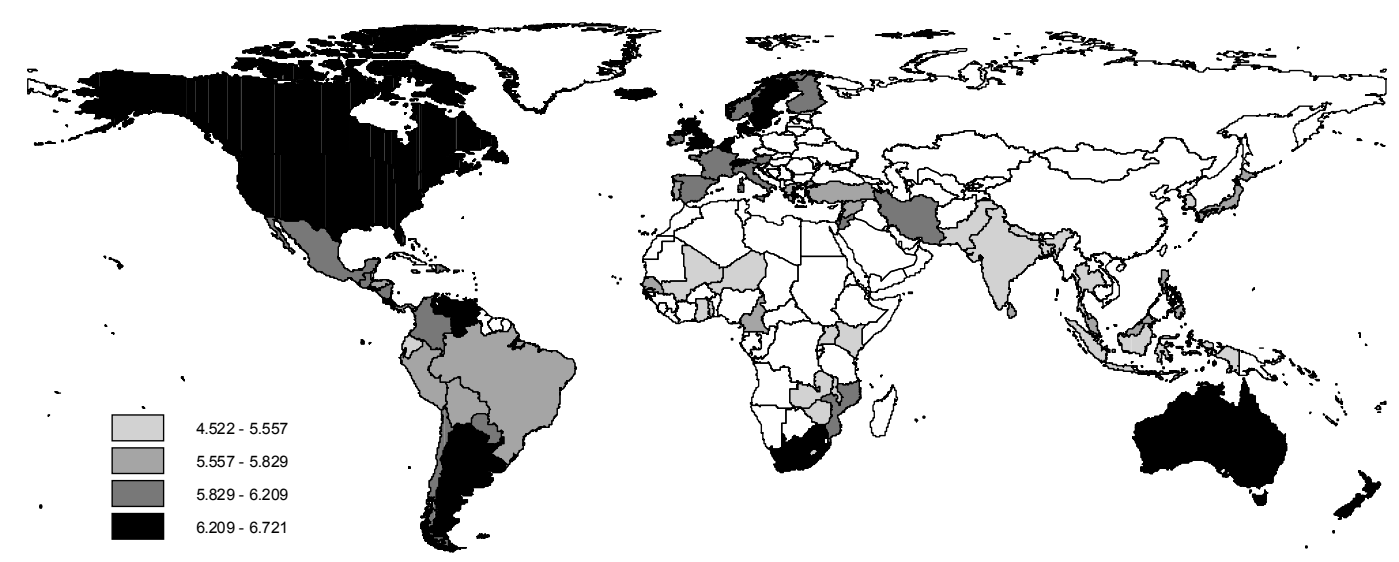

Figure 5: Distribution of schooling growth rates (1960-2000)

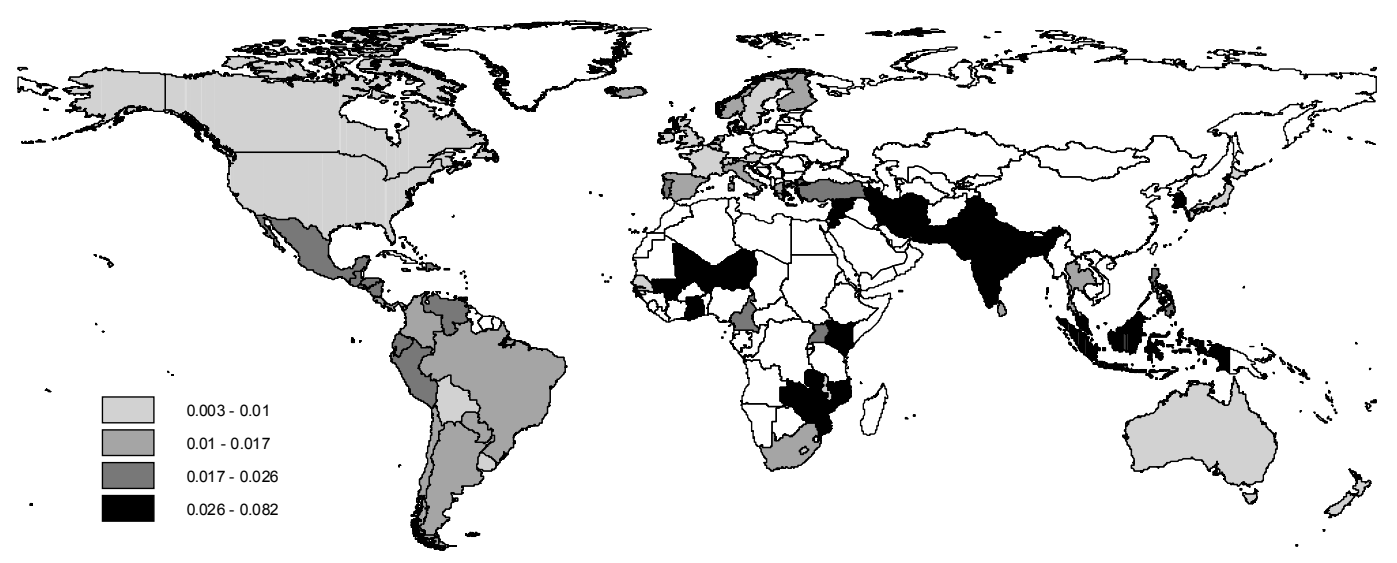


Figure 6: Distribution of $\ln$ (schooling) in 1960

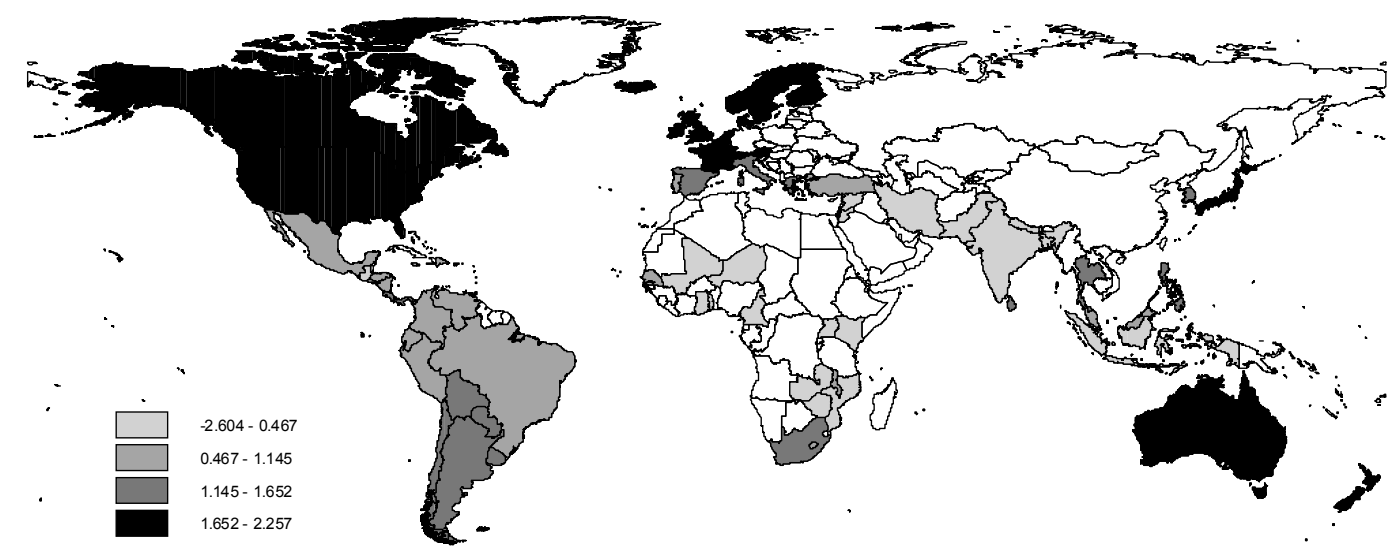

Figure 7: Moran scatterplot of TFP growth (1960-2000)

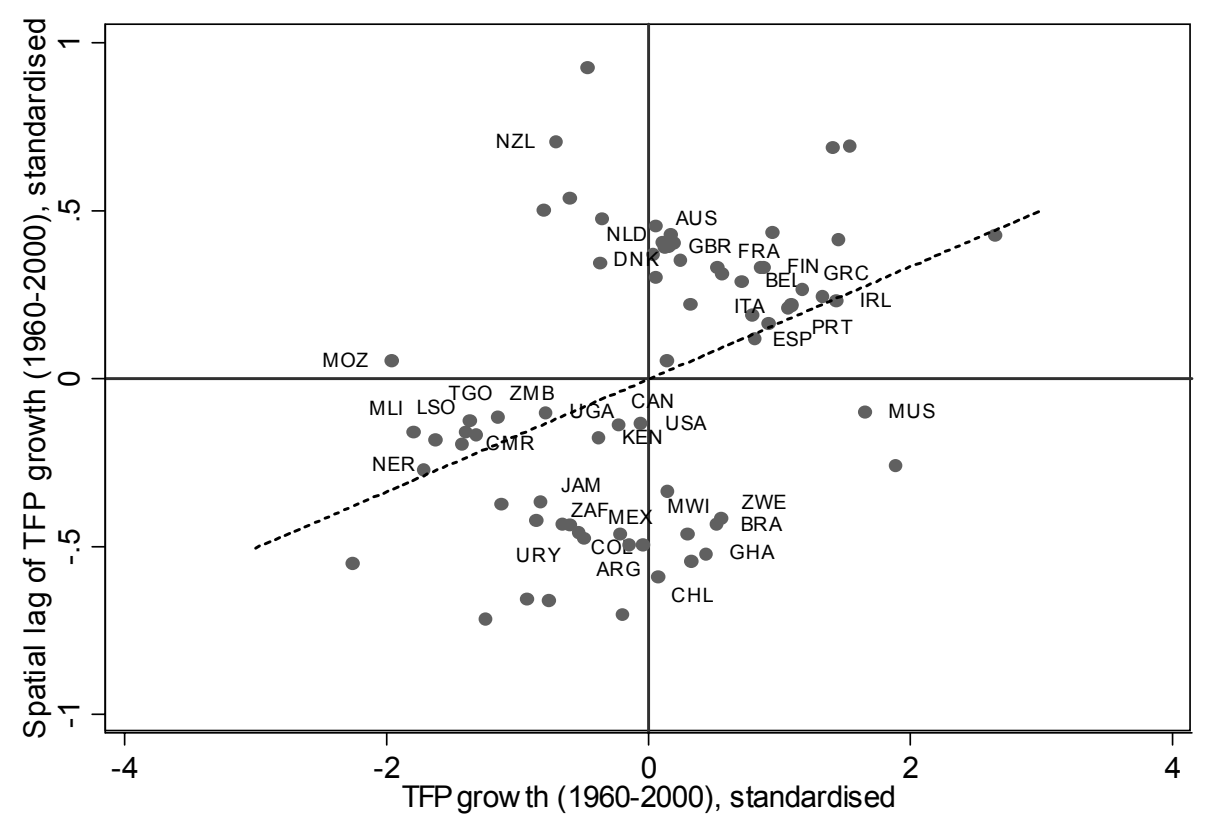


Figure 8: Moran scatterplot of $\ln (\mathrm{TFP})$ in 1960

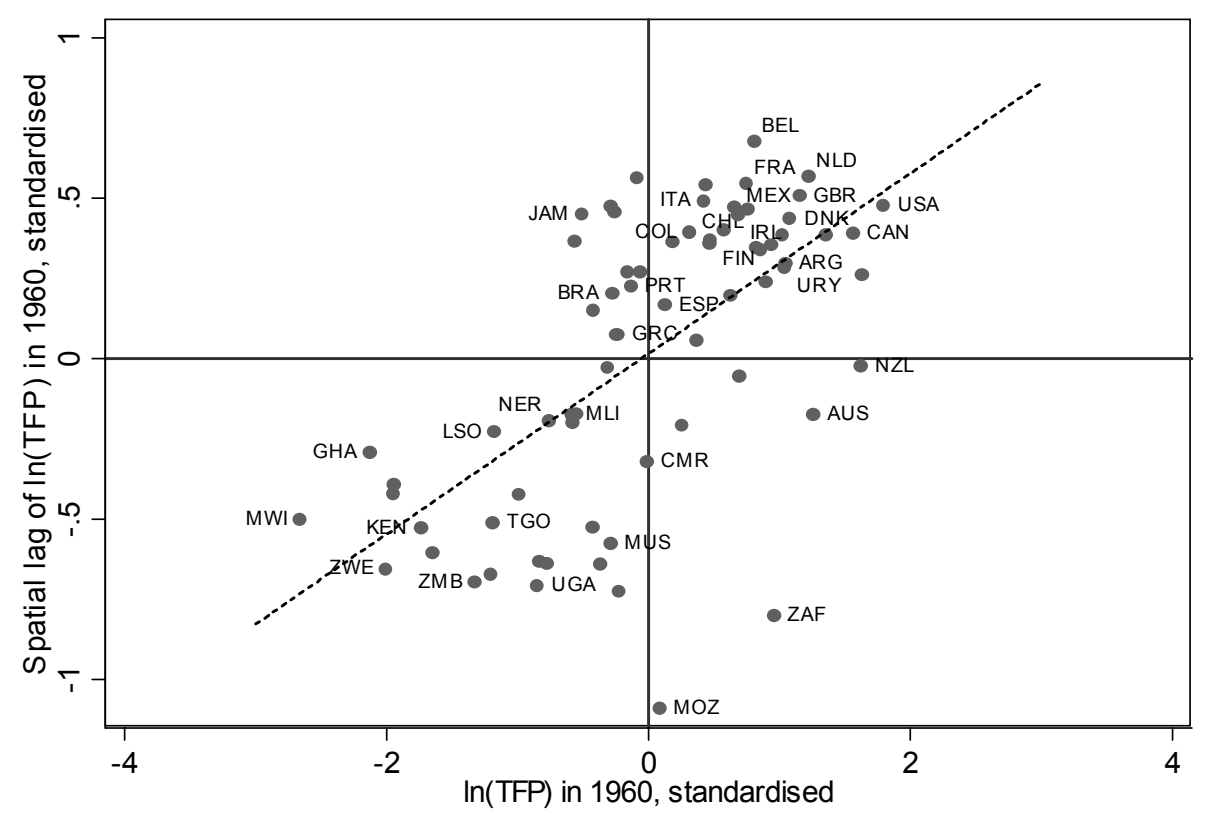


Figure 9: Moran scatterplot of $\ln (\mathrm{TFP})$ in 2000

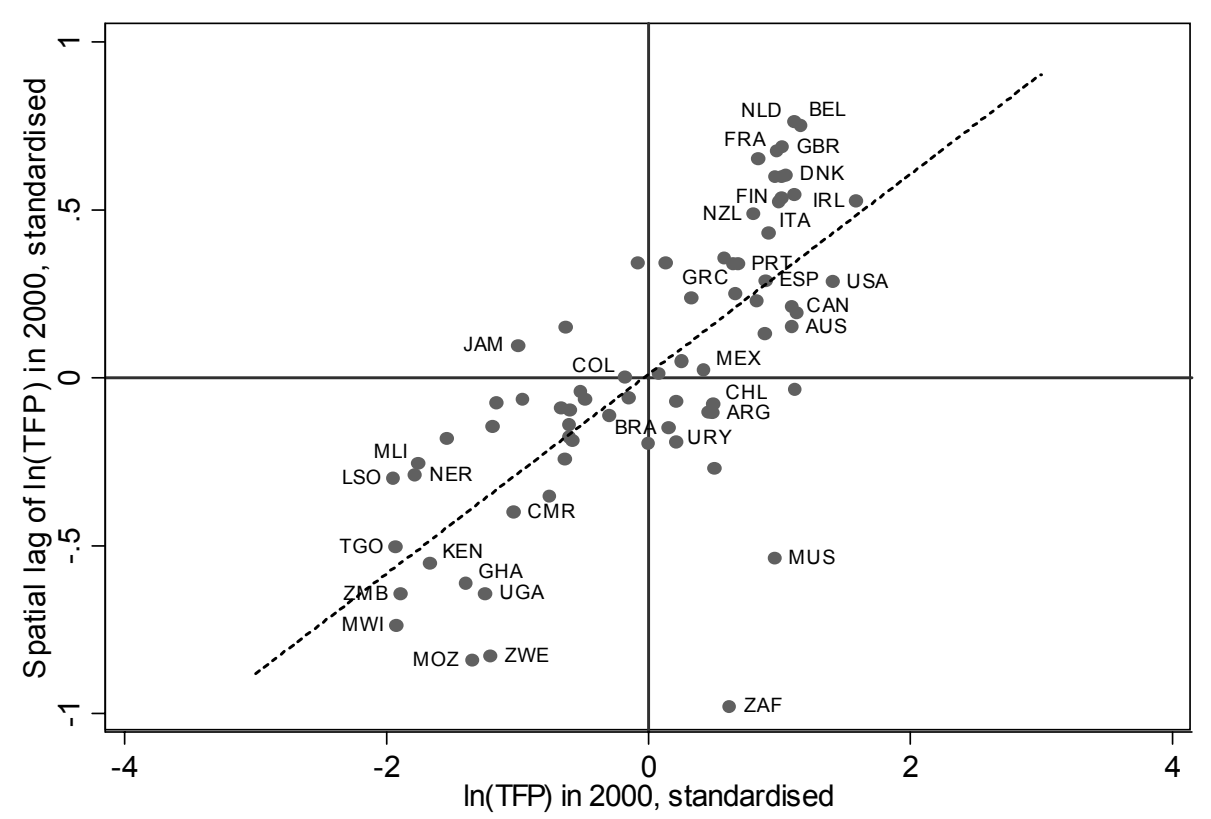

Figure 10: LISA cluster map for TFP growth rates (1960-2000)

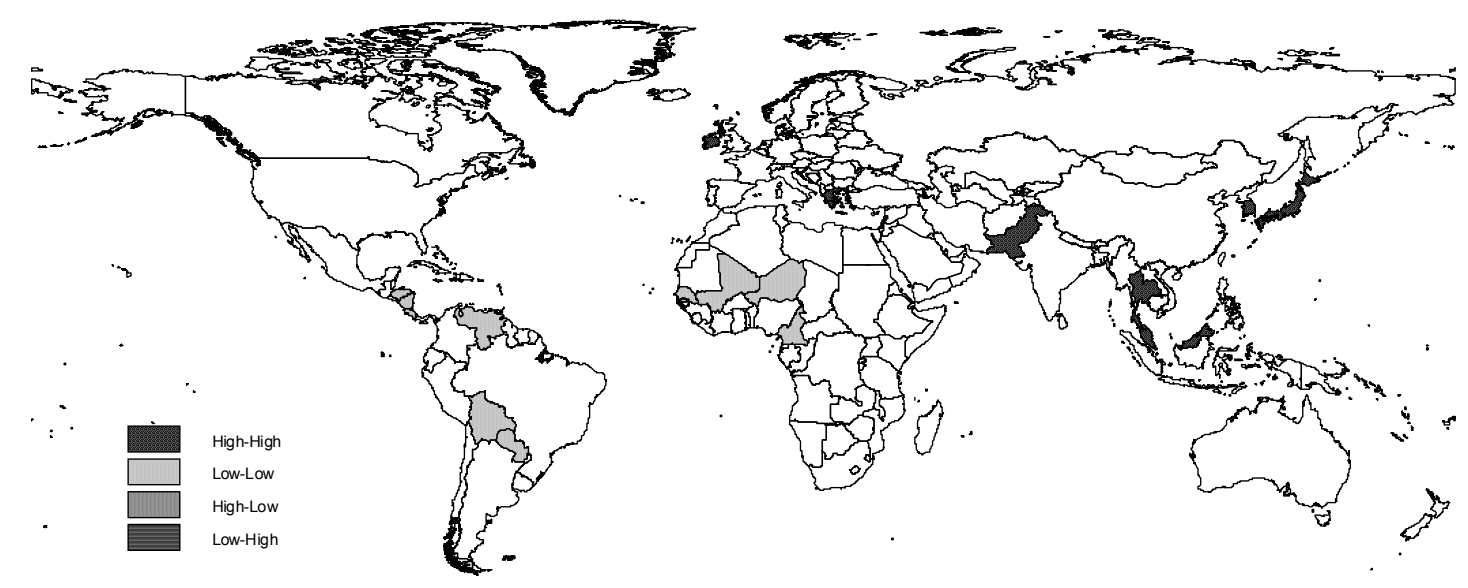


Figure 11: LISA cluster map for $\ln (\mathrm{TFP})$ in 1960

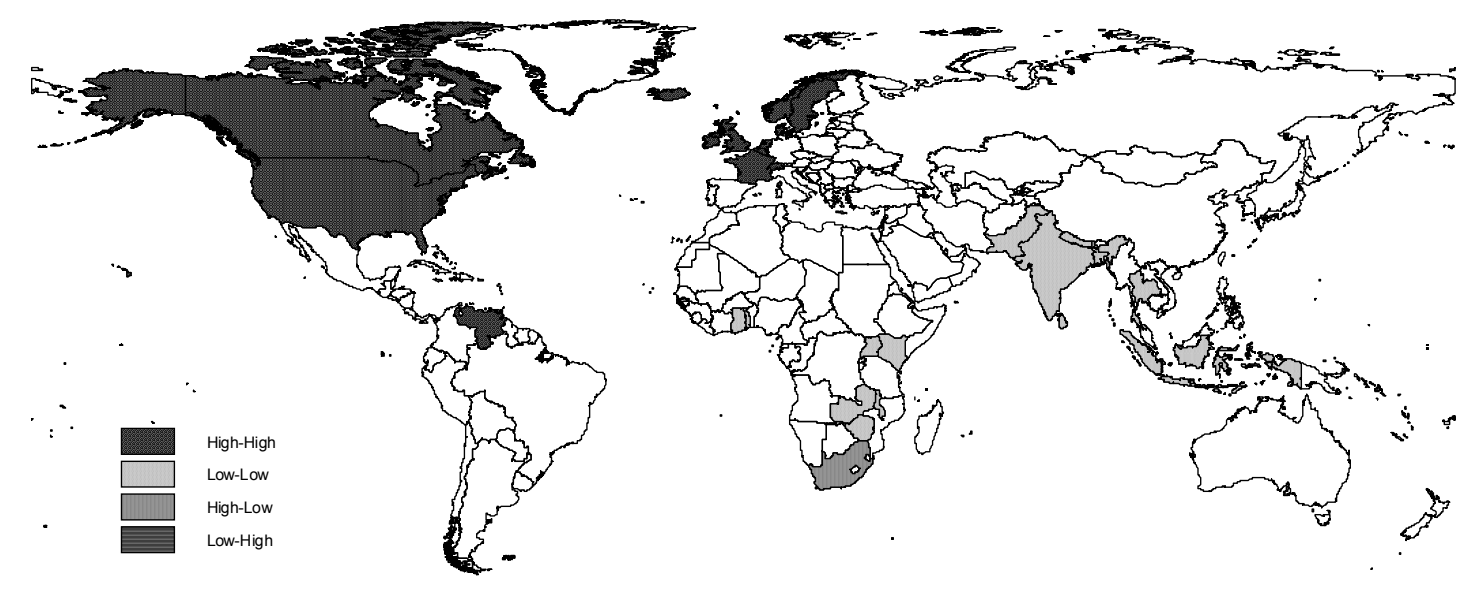

Figure 12: LISA cluster map for $\ln (\mathrm{TFP})$ in 2000

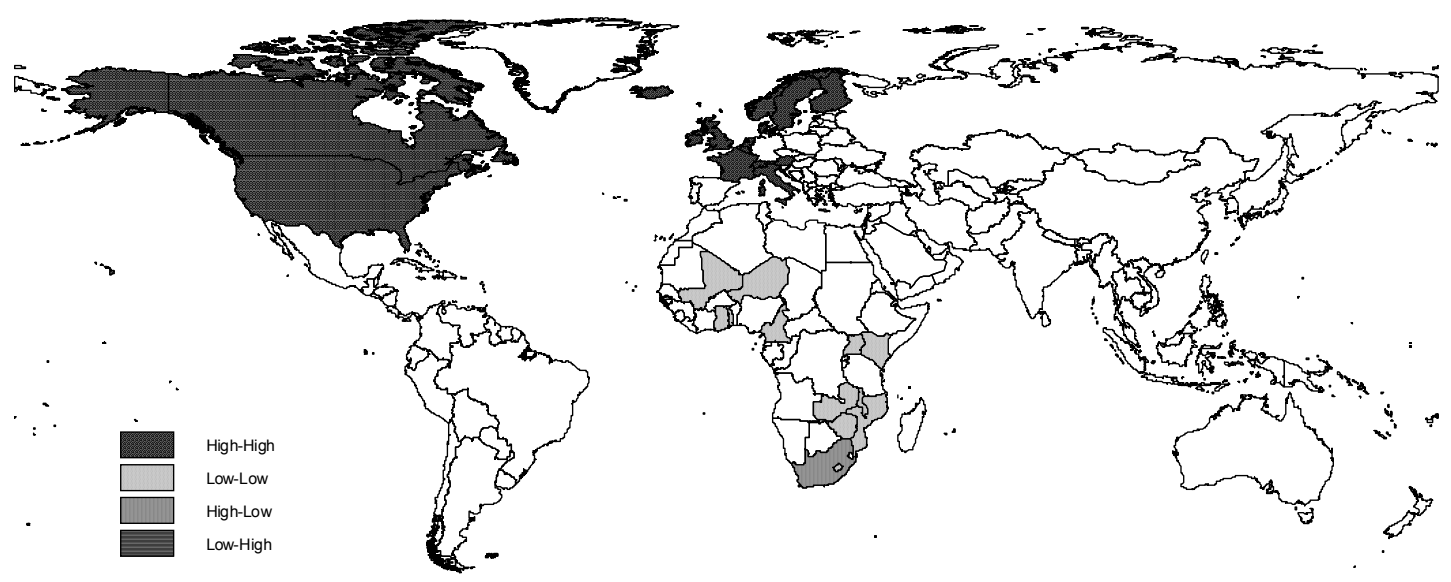


Figure 13: Distribution of the total effects for schooling in 1960

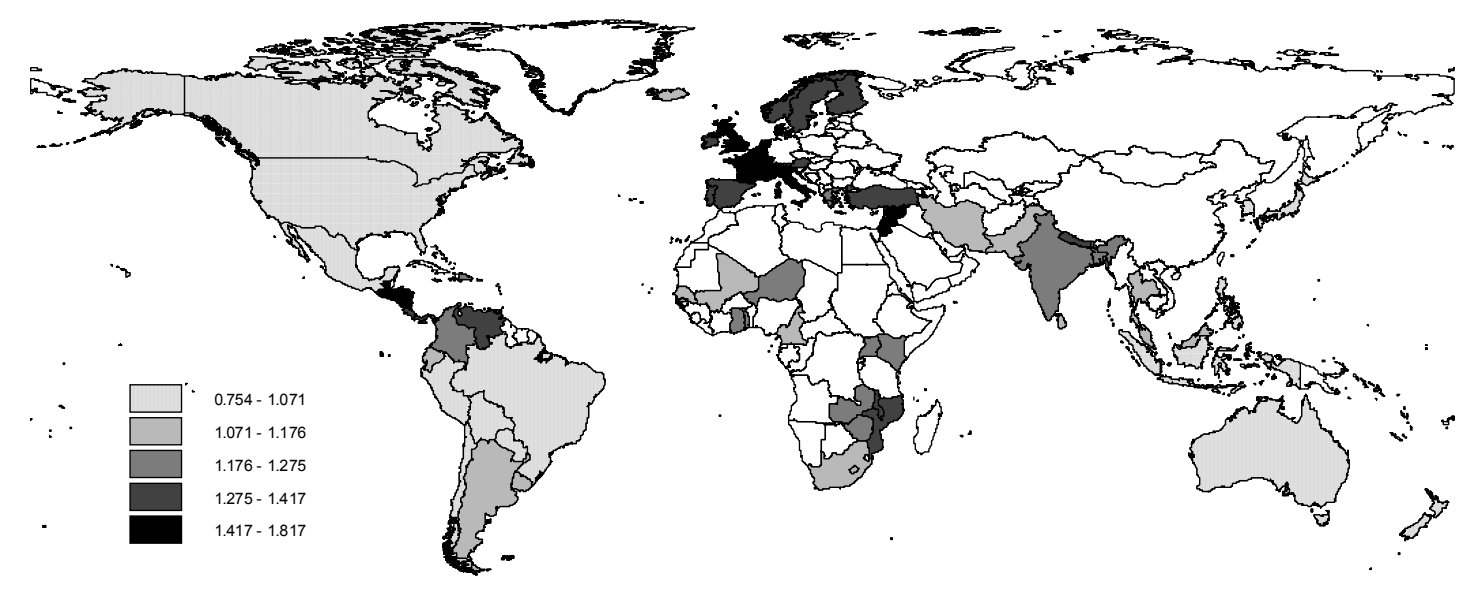

